\title{
A Conversation with Timothy Mitchison
}

\author{
INTERVIEWER: RICHARD SEVER \\ Assistant Director, Cold Spring Harbor Laboratory Press
}

\begin{abstract}
Timothy Mitchison is the Hasib Sabbagh Professor of Systems Biology, co-Director of the Initiative in Systems Pharmacology, and Deputy Chair for the Department of Systems Biology at Harvard Medical School.
\end{abstract}

\begin{abstract}
Richard Sever: Can you just remind everyone the arrangement of microtubules in the cell? In a typical animal cell, you have a radial array in interphase, and it changes during mitosis. What's the arrangement?
\end{abstract}

Dr. Mitchison: Microtubules are these long, thin protein polymers. We use the word "cytoskeleton" and they're sort of like the bones of the cell, although they're very dynamic. They grow and shrink, and they're transport tracks for material. Let's say a white blood cell is crawling around in your body: the microtubules radiate out from a central point called the centrosome and transport material and help the cell stay organized as it moves.

When a cell divides, the DNA compacts into individual chromosomes and the microtubules reorganize to build a structure called a mitotic spindle, which sort of looks spindle-shaped. The chromosomes attach to microtubules, and the microtubules actually pull the separated chromosomes into the two daughter cells. It's this beautiful dance of chromosomes, where microtubules are actually doing the work of moving. That was always my interest in cell division. It was less the DNA chromosome part, and more this beautiful dynamic organization of microtubules that orchestrates the movement.

Richard Sever: You mentioned that they're dynamic and we should think of them very differently from the image that the notion of a skeleton immediately conjures up. What controls the dynamics of how they grow and shrink at one end?

Dr. Mitchison: That was actually my big break in science. As a Ph.D. student, I got to be the first person to discover that microtubules grow and shrink continuously, powered by hydrolysis of a high-energy supply, GTP. We call that "dynamic instability." It's out of sync, so different microtubules are growing and shrinking. That allows them to rearrange very quickly. GTP hydrolysis also is the energy that the microtubules use to pull the chromosomes apart in mitosis.

Richard Sever: What's regulating those?

Dr. Mitchison: With a single microtubule growing and shrinking in the cell, we believe it's spontaneous, actually.
It's sort of probabilistic, although often when a microtubule hits the edge of the cell, it will mechanically trigger it to shrink. It's either spontaneous, or it hits a mechanical barrier. For the microtubules that touch a chromosome, they actually make a link through a structure on the DNA and there's a complicated protein assembly that holds on to the microtubules. They attract it, sort of like fly paper, and the microtubules join the DNA and then stick. So you could say that these proteins attached to the DNA are 'capturing' the microtubules.

Richard Sever: In both instances - during interphase before cell division, and at cell division - what's at the other end of the tubule? For that to work, it has to be anchored.

Dr. Mitchison: The canonical answer to that question is a structure called the centrosome, which is a small sphere in the center of the cell with a beautiful thing called a centriole in the middle, and the microtubules are nucleated there. They're generated there, and they're held on there. A lot of them are anchored to the centrosome, but it's more complicated than that. In fact, there isn't a centrosome in the meiotic spindles of the unfertilized frog egg. The minus ends of them - we call the ends that attach to the chromosomes the plus end and the other end, conventionally, the minus end - all gather together at the poles of the spindle and they're held in place probably by the motor protein dynein, that "walks down" and gathers them together. I'm not sure we know the details at that end.

Richard Sever: At some point, something must happen in the cell cycle to go from having one anchorage point to two to create the spindle.

Dr. Mitchison: Again, the conventional view of themand it's very true in a simple system like a budding or a fission yeast, where a lot of the genetics of the cell cycle were first worked out-is that the microtubule organizing center, which is the equivalent of the centrosome, actually splits in two and separates, so you have two points that grow out.

Richard Sever: So you have a replication event first.

Dr. Mitchison: You could call it a replication, but it's not a nucleic acid; it's a protein assembly. It's more like a

(C) 2017 Mitchison. This article is distributed under the terms of the Creative Commons Attribution-NonCommercial License, which permits reuse and redistribution, except for commercial purposes, provided that the original author and source are credited. 
growth and splitting. It's a little less precise than a replication. That's one way of doing it. But in the frog egg system we use, it seems to actually be more a case of self-organization. You have a jumble of microtubules, and they magically sort themselves out. In that case, the drive to be "bipolar" - having plus ends in the middle and minus ends at the extremes - a lot of that actually comes from a motor protein called kinesin-5 which, if two microtubules cross each other, the motor protein in the middle will push them apart and they self-organize.

Richard Sever: When most people think of motor proteins, they think of things running up and down these tubules transporting things. This is basically the same, but it's connecting two together?

Dr. Mitchison: Exactly. It transports one microtubule on another. The bipolar organization of the frog egg spindle is really created by one set of motors pushing the microtubules apart in the middle, and another set gathering the minus ends. It's a motor that transports one microtubule on another, and there are two flavors that go in opposite directions. That's a broad outline. How that works in detail, to build a mathematical model of it... I think we're not quite there yet.

Richard Sever: You mentioned looking at it in frog eggs. One feature of them is that they're extremely big compared with regular cells: about a millimeter. What was your reason for looking at frog eggs? Was it because of this size?

Dr. Mitchison: Not in the first place. I don't know how many people have seen it with their eyes, but a frog egg dividing is beautiful. I remember seeing it in biology class at school. I view a frog egg dividing as a kind of icon in biology. But for me, I was trained as a biochemist, and I like to use biochemical techniques. An appealing thing about a frog egg is you can get a whole flask full of them and grind them up, and have a lot of the proteins that make cells divide. You can have a whole bushel of those proteins. It's quantity. Also, for studying cell division, a frog egg is set up to divide. It does nothing except divide for the first twelve or thirteen divisions. Then, things get more complicated and the cells start changing into different cell types. In a frog egg, like other kinds of egg cells, the complement of protein inside them is very much specialized to allow them to divide. It's a rich source of cell division proteins. From a biochemical perspective, it's a good place to start. My friend, Bob Palazzo, instead of using frog eggs liked sea urchin eggs and clam eggs, and for the same reason. Except instead of getting a cupful like you can from frog eggs, you could get a bucketful. But frog eggs are a little closer to man. They're vertebrates. They're amphibians. So frog egg's a nice choice. It's somewhat close to human biology we would like to understand, and you can get it in biochemical quantities. That was really the reason for starting in frog eggs.

In the 1990s, we very much thought of frog eggs as a model for human cells dividing. We thought we were discovering conserved processes that are really the same in frog eggs and a dividing human embryo cell or a human cancer cell. In my head, I tried to minimize the differences. Now, as we know more about these different kinds of cells, the differences start to get interesting. One of the striking things about a frog egg is just how big it is. A typical dividing human cell might be 10 microns, so that's a 1/ 100th of a millimeter. It's a hundred times smaller linearly. By volume, you have to cube that number.

Richard Sever: So, a million times smaller.

Dr. Mitchison: By volume, right. One of the overarching problems in cell biology is how do molecules, which are tiny, organize cells, which are large. If the cell is really large, that problem is even more so. The frog egg divides every half hour, roughly, and in that half hour it has to assemble a physical structure. For example, the first cleavage in the frog egg cuts exactly down the middle, and the second cleavage cuts exactly at right angles. It's a system of molecules positioning themselves in spacemicrotubules, specifically - that positions that cleavage furrow, and how it can do it on this huge spatial scale is kind of mind-bending.

Richard Sever: What's the specific challenge for the organization of the microtubule structure in a large cell? Is there a structural challenge? And also, when does it stop?

Dr. Mitchison: There's a structural challenge and also a temporal challenge. One question is how long can a microtubule get? Can a microtubule grow right from the centrosome in the middle to the outside, which is roughly half a millimeter? We studied that process pretty carefully. We sometimes use eggs, but they're difficult to study because they're opaque and we have to fix them, and stain them, and clear them. But we often make an extract. We pack a bunch of eggs in a tube, crush them, and get this layer of cytoplasm and do a lot of the same biology. That's how most of our experiments go.

The egg is organized by radial arrays of microtubules called asters. They look like Fourth of July fireworks, the kind that shoots a whole bunch of lines out from a central point. Going in, we assumed that the microtubules would go all the way from the middle to the outside. But when we look carefully using proteins that marked the tips of the microtubules, we realized that actually the asters are made up of a whole lot of little microtubules that are nested. So they grow out from the sides of each other.

Richard Sever: So, it's more like a tree?

Dr. Mitchison: Exactly. There are bushes where every shoot grows from the roots right up, but if you want to build a big tree, you make branches. I think the reason you have to do that just may be mechanical, actually. Just like with a tree, it probably wouldn't be physically possible to build it with every shoot going down to the root.

Richard Sever: Does that mean you need different things in frogs to create the branches more than you would in a human?

Dr. Mitchison: It's a good question. We haven't nailed the molecular basis of creating a microtubule. Nucleating it, 
we call it. You seed it. We think there's a kind of molecular seed, and we have not solved the molecular mechanism of this growth from the side of microtubules. I would like to do that. We don't have, for example, genetics in frog eggs, so while it's a really good system for microscopy, for studying the physiology of proteins you already know about, it's not quite as good for discovering new proteins for the first time. You can, but other systems tend to be better for that.

Richard Sever: Returning to what you were saying earlier, you have this distance problem, but then a geometry problem as well.

Dr. Mitchison: The geometry problem really fascinates me. How do you find the middle, for example? From the outside, when a frog egg divides you see these cleavage furrows that cut down. They cut the egg into two, and then in four. It turns out that the cleavage furrows, where they're positioned, is when two of these microtubule asters touch each other, where the plus ends overlap. Imagine two domes touching each other, and in the middle, that defines a plane. There're several proteins we've been working on that are recruited at that plane. As the asters grow, that plane grows out to the surface. When it touches the surface, it stimulates the cortex to contract. Understanding this plane that's formed where the two asters touch has been one of the many things that we do.
Richard Sever: And the fact that it's perpendicular to the axis is determined by the microtubules?

Dr. Mitchison: Yes. You have to know the positions of the centers of the asters, and the positions of the microtubules. One part is that when the microtubules grow into something that is a boundary, they stop growing. When the two asters grow into each other, that's another boundary. They stop growing in the middle. We've been working on that.

A second factor is how the nucleating sites are positioned. We've made less progress on that. We know another motor protein, dynein, is involved in that. For example, one version of the problem is that you've cleaved the egg in two. Now, the next furrow's going to be at ninety degrees. Where does that angle come from? It comes from finding the long axis of the cell, and we think that the geometry of the microtubules controls the net forces that are acting on them. That's what positions the next furrow. There's actually a lot we still don't know about that. I don't want to pretend we know more than we do.

One of the fun things is there are people who have been looking at frog eggs and wondering how they make those cleavage furrows for more than a hundred years, so there are lovely experiments we've referred to from the 1890 s and 1910 s. We actually repeated those experiments. We got the same results, but we're able to take it further now that we have some of the molecules. That stepping in the tracks of the people who came before us is part of the fun of it. 


\section{$\$_{\text {CSH\& }}^{\infty}$ Cold Spring Harbor Symposia SYMPOSIA}

\section{A Conversation with Timothy Mitchison}

Cold Spring Harb Symp Quant Biol 2017 82: 406-408 originally published online May 4, 2018 Access the most recent version at doi:10.1101/sqb.2017.82.035378

Creative This article is distributed under the terms of the

Commons http://creativecommons.org/licenses/by-nc/4.0/, which permits reuse and

License redistribution, except for commercial purposes, provided that the original author and source are credited.

Email Alerting Receive free email alerts when new articles cite this article - sign up in Service the box at the top right corner of the article or click here. 